\title{
Description and initial evaluation of an educational and psychosocial support model for adults with congenitally malformed hearts
}

\author{
Helén Rönning, Niels Erik Nielsen, Eva Swahn and Anna Strömberg
}

\section{Linköping University Post Print}

N.B.: When citing this work, cite the original article.

Original Publication:

Helén Rönning, Niels Erik Nielsen, Eva Swahn and Anna Strömberg, Description and initial evaluation of an educational and psychosocial support model for adults with congenitally malformed hearts, 2011, Patient Education and Counseling, (83), 2, 247-251.

http://dx.doi.org/10.1016/j.pec.2010.06.015

Copyright: Elsevier Science B.V., Amsterdam.

http://www.elsevier.com/

Postprint available at: Linköping University Electronic Press

http://urn.kb.se/resolve?urn=urn:nbn:se:liu:diva-68675 


\section{Description and initial evaluation of an educational and psychosocial support model for adults with congenitally malformed hearts}

Short title: Education and psychosocial support for congenitally malformed hearts

Author: Helén Rönning ${ }^{1}$, Niels Erik Nielsen ${ }^{3}$, Eva Swahn ${ }^{2}$ Anna Strömberg ${ }^{1}$

${ }^{1}$ Department of Medical and Health Sciences, Division of Nursing Science, Linköping University, Sweden

${ }^{2}$ Department of Medical and Health Sciences, Division of Cardiology, Linköping University, Sweden

${ }^{3}$ Department of Cardiology, Linköping University Hospital, Sweden

Address for Correspondence: Helén Rönning, Department of Cardiology, Linköping University Hospital, S-581 85 Linköping, Sweden. Tel,: +46 101038779; fax: +46 101032224. E-mail: helen.ronning@liu.se

Keywords: Patient education, information, hospital outpatient clinic, nursing, computer-based education, Competence based education 
Abstract

Objective: Various programmes for adults with congenitally malformed hearts have been developed, but detailed descriptions of content, rationale and goals are often missing. The aim of this study was to describe and make an initial evaluation of a follow-up model for adults with congenitally malformed hearts, focusing on education and psychosocial support by a multidisciplinary team (EPS).

Methods: The model is described in steps and evaluated with regards to perceptions of knowledge, anxiety and satisfaction.

Results: The EPS model included a policlinic visit to the physician/nurse (medical consultation, computer-based and individual education face-to-face as well as psychosocial support) and a 1-month telephone follow-up. Fifty-five adults (mean age 34, 29 women) with the nine most common forms of congenitally malformed hearts participated in the EPS model as well as the 3-months follow-up. Knowledge about congenital heart malformation had increased in $40 \%$ of the participants at the 3-months follow-up.

Conclusion: This study describes and evaluates a model that combines a multidisciplinary approach and computer-based education for follow-up of adults with congenitally malformed hearts. The EPS model was found to increase self-estimated knowledge, but further evaluations need to be conducted to prove patient-centred outcomes over time. Practice implications: The model is now ready to be implemented in adults with congenitally malformed hearts. 


\section{Introduction}

Adults with congenitally malformed hearts often have a poor level of knowledge about various aspects of their cardiac condition and there is a lack of educational materials for this group ${ }^{1-5}$ To date, education has often been given as verbal information, complemented with pictures of the heart and copies from medical charts, provided by the responsible cardiologist ${ }^{6}$. Patient education/computer-based education has been shown to increase knowledge and/or management of the disease in people with chronic diseases ${ }^{7-10}$. We have constructed a followup model for adults with congenitally malformed hearts that contains medical consultation, education and psychosocial support by a multidisciplinary team (EPS). The aim of this study was to describe and make an initial evaluation of a follow-up model for adults with congenitally malformed hearts, focusing on education and psychosocial support by a multidisciplinary team (EPS).

\section{Methods}

Adults with uncomplicated congenitally malformed hearts (ventricular septal defect, atrial septal defect, coarctation of the aortae, aortic valve stenosis) and complicated congenitally malformed hearts (tetralogy of Fallot, complete transposition of the great arteries, congenitally corrected transposition of the great arteries, Ebstein anomaly and Eisenmenger syndrome) can be offered the EPS model. The EPS model is described in steps including a visit to the physician/nurse and 1-month telephone follow-up (Table 1). Data were collected from the participants regarding perceptions of knowledge, anxiety and satisfaction related to the EPS model before and after the different steps (Table 2).

Please insert Table 1 and 2 here

\section{Results}

\subsection{Part 1: Visit to the physician}


Before the participants received the EPS model, they completed a questionnaire to test their degree of knowledge regarding their cardiac condition; the Knowledge scale for Adults with Congenitally Malformed Hearts (KnoCoMH) (developed from the Leuven Knowledge Scale $\left.{ }^{4}\right)$ and a questionnaire to investigate symptoms of anxiety and depression, Hospital Anxiety and Depression Scale, (HADS) ${ }^{11}$. The instruments were analysed and the results used in the participant's individual education in part two.

During the visit they underwent clinical evaluations and/or echocardiography and/or exercise tests. Following the evaluations, the physician provided the participants with the results, allowing time for questions.

\subsection{Part 2: Visit to the specialised nurse}

The next step was the visit to the nurse. First, t education was provided through a computerbased educational program followed by individual education face-to face and psychosocial support.

\subsubsection{The computer-based educational program}

The computer-based educational program for adults with the ten most common forms of congenitally malformed hearts has been developed and evaluated by a multidisciplinary team and adults suffering from these diseases (table 3). The program was developed as a complement to verbal information in order to gain a more complete understanding of congenitally malformed hearts. All of the ten malformations in the program have their own module. Each module consists of eight main areas and subheadings (Table 4).

The nurse introduced the participant to the computer-based educational program containing information about their particular congenital cardiac malformation. This information was downloaded to a CD. The participant and the nurse started by looking at the cover (Picture 1) and the contents list detailed on the back (Table 4). 
On the inside of the cover was the name of the cardiac malformation, the name and year of any surgery, or if they had been recommended endocarditis prophylactics. The physician's or nurse's phone number was also on the cover. The participant then started the computer-based educational program and the nurse demonstrated how to navigate through the main areas (Picture 2) and subheadings (Picture 3). They also looked at an example of the self-conducted test (Picture 4) that ended every main area (Table 4). The participant then ran the entire program on his/her own. Depending on the physician's recommendations of endocarditis prophylactics, the participants included or excluded the main area Endocarditis Prophylactics. The nurse was still around to provide any assistance during the 60 minutes when the participant ran the program

Please insert Table 3 and 4 and Pictures 1-4 here

\subsubsection{Individual education and psychosocial support}

The nurse and the participant looked through the results of the knowledge questionnaire, KnoCoMH that had been completed before visiting the physician. They discussed the contents of the computer-based educational program and the questions in the $\mathrm{KnoCoMH}$ from the participant's perspective. Through this procedure both the participant and the nurse gained an understanding of the participant's understanding of their malformation and knowledge gaps. The KnoCoMH dealt with areas such as general knowledge about the cardiac condition (name, symptoms, cause/heredity, physical activity) and specific knowledge such as medication, endocarditis prophylactics, contraceptives and pregnancy. The participant's individual need for knowledge was registered by the nurse during the discussion regarding the KnoCoMH and the computer-based educational program.

The next step was to evaluate the need for psychosocial support. This was achieved through 26 questions previously used by Kampuis et al ${ }^{12}$. The questions covered different subjects such as life/health insurance, education, employment, sport, and other daily activities (Table 
5). The questions were discussed with the participant and if there were problems the nurse asked if they were related to the malformation. Only problems related to the cardiac condition were registered. The discussion around the participant's situation, cardiac malformation and new knowledge contributed to a willingness and motivation to improve self-care. Individual goals were set, and an individual care plan was developed to reach the goal. All participants were given a contact card for the nurse. The next step was the 1-month follow-up.

If the results of the HADS questionnaire showed symptoms of anxiety/depression (scale score $8-10=$ borderline for symptoms of anxiety/depression, $>11$ clinically significant anxiety/depression ${ }^{11}$ ) the nurse addressed this with the participant and contacted the social worker in the multidisciplinary team. This team consisted of a physiotherapist, dietician, hospital social worker, cardiologist, gynaecologist, anesthesiologist, obstretician and pediatrician. If needed, the nurse contacted participants in the multidisciplinary team to organise an appointment. The member of the multidisciplinary team whowas contacted, was responsible to follow up the participant's goal.

Everyone in the multidisciplinary team remained in contact with the physician in charge in case there were questions regarding the participant's situation in relation to the congenitally malformed heart.

Please insert Table 4 here

\subsubsection{One-month follow-up}

The nurse phoned the participants as a follow-up one month after the visit to the hospital outpatient clinic. The reason for this follow-up was to check if the participants had any questions, if the goal set had been reached and how to plan for the future. The participants could also make contact with the nurse if needed. Further follow-up was planned according to the participants' situation

\subsection{Initial evaluation}


Fifty-five adults have passed the EPS model. Mean age was 34 years (range 19-74). Twentynine participants were women. Before passing the EPS model, $47 \%(25 / 53)$ perceived their knowledge of their cardiac condition to be "good" or "excellent", three months later these numbers had increased to $89 \%$ (41/46). Regarding symptoms of anxiety, 38\% (20/52) perceived "some anxiety" or "much anxiety" in connection with their cardiac condition before the EPS model. After three months this remained unchanged ( $39 \%, 18 / 46)$. Directly after passing the EPS model, $88 \%$ (45/51) perceived their satisfaction with the combination of the visit to the physician and the nurse to be "very good" or "excellent" but after three months this number had decreased to $75 \%(33 / 44)$ (Table 6).

Please insert Table 6 here

\section{Discussion and conclusion}

\subsection{Discussion}

Education and/or psychosocial support have previously been studied in connection with chronic diseases such as heart failure ${ }^{13}$, asthma ${ }^{14}$, ischemic heart disease ${ }^{15}$ ) as well as in adults with congenitally malformed hearts ${ }^{16}$. Computer-based education and psychosocial support have shown to improve effects in education and self-management programmes ${ }^{17-18}$. To the best of our knowledge a model like EPS has never been described before. The EPS model is developed from the theory of constructivism ${ }^{19-20}$ using a competence-based course $\operatorname{design}^{21}$ that includes computer-based, individual education face-to-face and psychosocial support. In accordance with the educational theory of constructivism, the focus of the EPS model is to support adults with congenitally malformed hearts in understanding their cardiac condition, by building the education and psychosocial support on relevance and prior knowledge (competence-based course design) ${ }^{19-21}$. To promote learning and self-management it is important to engage the participant by taking the individual's perspective rather than the disease perspective ${ }^{61722}$. The computer-based educational program used in the EPS model 
has been developed and tested in accordance with the cognitive theory of multimedia learning and the theory of cognitive load perspective ${ }^{23-24}$. This means that the program use an easy language text, pictures, animations and sounds to engage the participants in understanding their malformed hearts.

The strengths with our study are: 1) The content of our EPS model is described in detailed to allow thorough understanding of the content and theoretical framework of the intervention and 2) The participants' perceptions are assessed before and 3 months after the EPS model 3) The participants' knowledge is evaluated before the EPS model and 4) The individual education is based on the knowledge evaluation. The psychosocial support was developed from the person's own perspective, i.e. the education and psychosocial support was individually targeted to the personal view. One weakness of our approach was that only adults with the ten most common diagnoses in congenitally malformed hearts could participate in the model. The reason for this was that we chose to start developing the computer-based educational program only for ventricular septal defect, atrial septal defect, coarctation of the aortae, aortic valve stenosis, tetralogy of Fallot, complete transposition of the great arteries, congenitally corrected transposition of the great arteries, single ventricle, Ebstein anomaly and Eisenmenger syndrome.

\subsection{Conclusions}

This is the first study to describe and evaluate a model combining a multidisciplinary approach and computer-based education as follow-up for adults with congenitally malformed hearts. Our EPS model fulfils the recommendations of international guidelines. Further studies are needed to test the outcomes of the EPS model regarding long-term increase in knowledge and other patient- centred outcomes.

\subsection{Practice implications}

The model is now ready to be implemented in adults with congenitally malformed hearts. 


\section{Competing interests}

The authors declare that they have no conflicts of interest.

\section{Authors' contributions}

HR initiated and planned the study and drafted the manuscript. ES, AS, and NN participated in the planning of the study and writing the manuscript. All authors read and approved the final manuscript.

\section{Acknowledgements}

This study was supported by grants from The Research Council in South-East Sweden (FORSS), Heart-Lung Foundation and Östergötland County Council.

I confirm that all personal identifiers have been removed or disguised so that the person described is not identifiable and cannot be identified through the details of the story. 


\section{References}

1. Shebani SO, Miles HF, Simmons P, Stickley J, De Giovanni JV. Awareness of the risk of endocarditis associated with tattooing and body piercing among patients with congenital heart disease and paediatric cardiologists in the United Kingdom. Arch Dis Child 2007;92(11):1013-4. .

2. Chessa M, De Rosa G, Pardeo M, Negura GD, Butera G, Feslova V, et al. Illness understanding in adults with congenital heart disease. Ital Heart J 2005;6(11):895-9.

3. Dore A, de Guise P, Mercier LA. Transition of care to adult congenital heart centres: what do patients know about their heart condition? Can J Cardiol 2002;18(2):141-6.

4. Moons P, De Volder E, Budts W, De Geest S, Elen J, Waeytens K, et al. What do adult patients with congenital heart disease know about their disease, treatment, and prevention of complications? A call for structured patient education. Heart 2001;86(1):74-80.

5. Veldtman GR, Matley SL, Kendall L, Quirk J, Gibbs JL, Parsons JM, et al. Illness understanding in children and adolescents with heart disease. Heart 2000;84(4):395-7.

6. Rönning H, Nielsen NE, Swahn E, Strömberg A. Educational needs in adults with congenitally malformed hearts. Cardiol Young 2008;18(5):473-9. .

7. Murray E, Burns J, See TS, Lai R, Nazareth I. Interactive Health Communication Applications for people with chronic disease. Cochrane Database Syst Rev 2005(4):CD004274.

8. Bussey-Smith KL, Rossen RD. A systematic review of randomized control trials evaluating the effectiveness of interactive computerized asthma patient education programs. Ann Allergy Asthma Immunol 2007;Jun;98(6):507-16.

9. Strömberg A, Dahlström U, Fridlund B. Computer-based education for patients with chronic heart failure. A randomised, controlled, multicentre trial of the effects on knowledge, compliance and quality of life. Patient Educ Couns 2006;64(1-3):128-35. .

10. Beranova $E$, Sykes C. A systematic review of computer-based softwares for educating patients with coronary heart disease. Patient Educ Couns 2007;66(1):21-8. . 
11. Caci H, Bayle FJ, Mattei V, Dossios C, Robert P, Boyer P. How does the Hospital and Anxiety and Depression Scale measure anxiety and depression in healthy subjects? Psychiatry Res 2003;118(1):89-99.

12. Kamphuis M, Verloove-Vanhorick SP, Vogels T, Ottenkamp J, Vliegen HW. Disease-related difficulties and satisfaction with level of knowledge in adults with mild or complex congenital heart disease. Cardiol Young 2002;12(3):266-71.

13. Ditewig JB, Blok H, Havers J, van Veenendaal H. Effectiveness of self-management interventions on mortality, hospital readmissions, chronic heart failure hospitalization rate and quality of life in patients with chronic heart failure: A systematic review. Patient Education and Counseling 2010 (mars).

14. Gibson PG, Powell H, Coughlan J, Wilson AJ, Abramson M, Haywood P, et al. Self-management education and regular practitioner review for adults with asthma. Cochrane Database Syst Rev 2003(1):CD001117.

15. Ebrahim S, Beswick A, Burke M, Davey Smith G. Multiple risk factor interventions for primary prevention of coronary heart disease. Cochrane Database Syst Rev 2006(4):CD001561.

16. Berg SK, Hertz PG. Outpatient Nursing Clinic for Congenital Heart Disease Patients. Journal of Cardiovascular Nursing 2007;22(6):488.

17. Barlow J, Wright C, Sheasby J, Turner A, Hainsworth J. Self-management approaches for people with chronic conditions: a review. Patient Educ Couns 2002;48(2):177-87.

18. Mayer RE. Introduction to Multimedia Learning. In: The Cambridge Handbook of Multimedia Learning. New York: Cambridge University Press, 2005.

19. Grunwald T, Corsbie-Massay C. Guidelines for cognitively efficient multimedia learning tools: educational strategies, cognitive load, and interface design. Acad Med 2006;81(3):213-23. 20. Bradley P, Postlethwaite K. Simulation in clinical learning. Med Educ 2003;37(Suppl 1):1-5. 21. Toohey S. Designing Courses for Higher Education. Berkshire, United Kingdom: The Society for Research into higher Education \& Open University Press, 1999. 
22. Kralik D, Koch T, Price K, Howard N. Chronic illness self-management: taking action to create order. Journal of Clinical Nursing 2004;13(2):259-67.

23. Sweller J. Implications of Cognitive Load Theory for Multimedia Learning. In: The Cambridge Handbook of Multimedia Learning. . New York: Cambridge University Press, 2005.

24. Mayer RE. Cognitive Theory of Multimedia Learning. In: The Cambridge Handbook of Multimedia Learning. New York: Cambridge University Press, 2005. 


\section{Table 1}

The flow in the EPS model

Part 1: Visit to the physician

Part 2: Visit to the specialised nurse

The computer-based educational program

Individual education and psychosocial support

EPS model = Education and Psychosocial Support by multidisciplinary team 


\section{Table 2}

Questions about the participants own perception about their knowledge, anxiety and satisfaction.

How do you perceive your knowledge about your cardiac condition? ${ }^{a, b}$

How do you perceive your current anxiety with regards to your cardiac condition? ${ }^{\text {a,b }}$

How do you perceive your current satisfaction regarding your meeting with a physician and a nurse? ${ }^{c, b}$

${ }^{a}$ Baseline before EPS model.

${ }^{\mathrm{b}} 3$ months.

${ }^{c}$ Baseline after visit at the physician/nurse. 
Table 3

Modules in the Computer-based Educational Program.

Ventricular septal defect

Atrial septal defect

Coarctation of the aortae

Aortic valve stenosis

Tetralogy of Fallot

Complete transposition of the great arteries

Congenitally corrected transposition of the great arteries

Single ventricle

Ebstein anomaly

Eisenmenger syndrome 
Table 4

Eight main areas and their subheadings in each of the 10 modules in the Computer-Based Educational Program

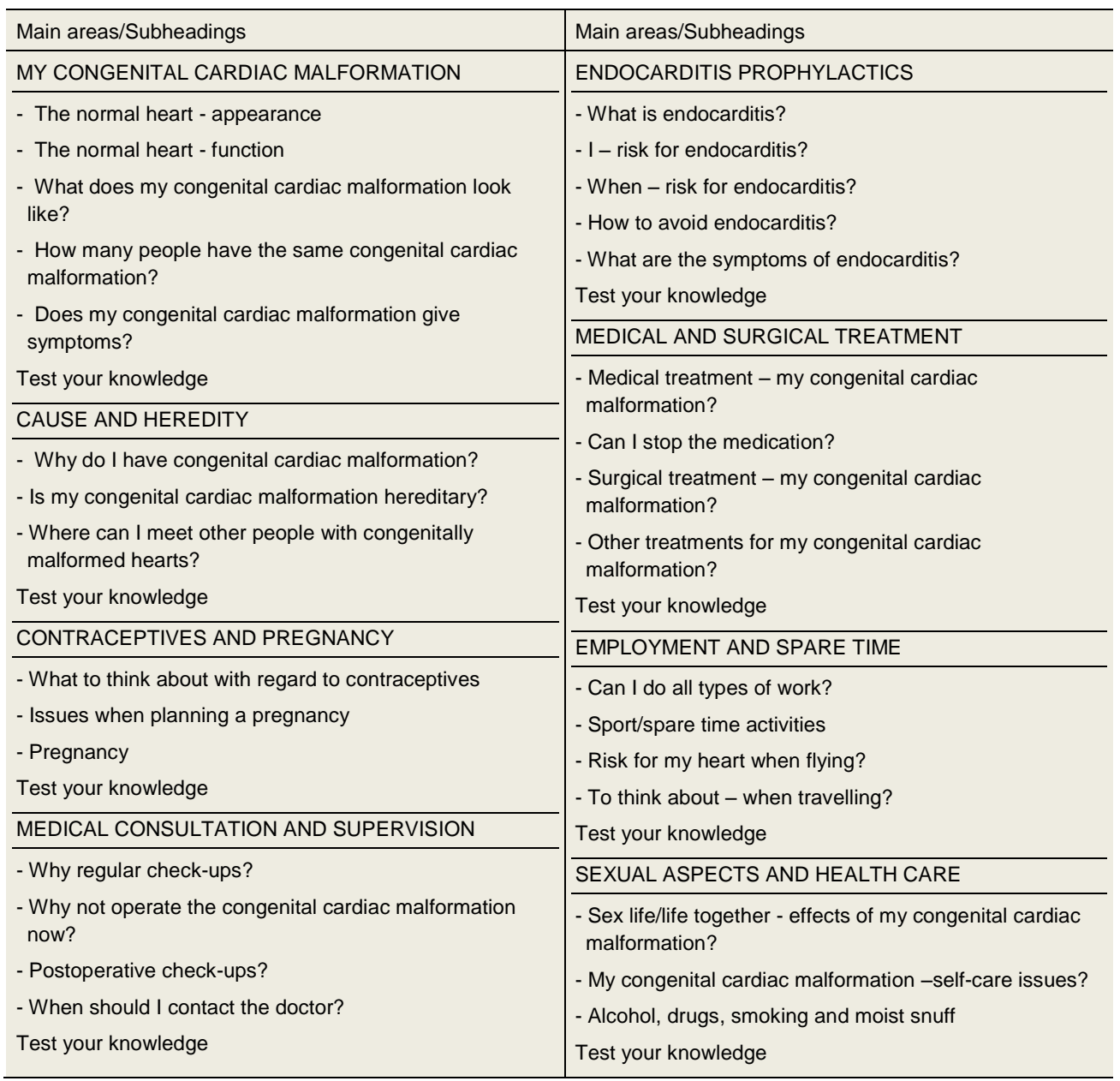


Table 5. Questions during Phase 2; Difficulties in daily life related to

the congenital cardiac malformation.

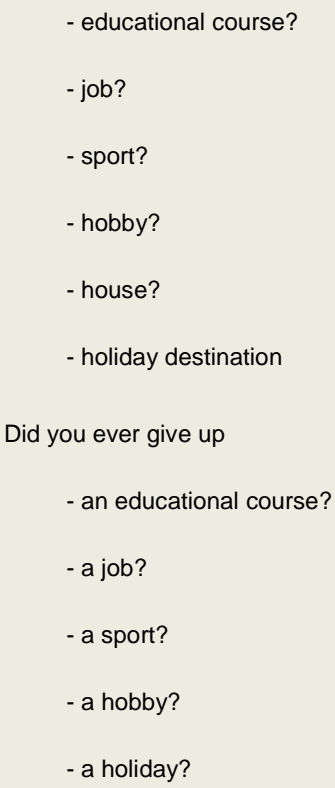

Were you ever prevented from

- applying for a driving licence?

- taking out a mortgage policy?

- taking out a life insurance policy?

- taking out a health insurance policy?

Did you ever have to pay a higher premium than other people for

- a mortgage?

- a life insurance?

- a health insurance? 



\section{Table 6}

Perceptions about knowledge, anxiety before/after the EPS model and satisfaction with EPS model at baseline and after 3 months, presented in numbers and percentage.

\begin{tabular}{llllllll}
\hline \multicolumn{7}{c}{ How do you perceive your knowledge about your cardiac condition? } \\
\cline { 2 - 7 } & Excellent & Very good & Good & Fairly good & Poor & Very poor & Total \\
\hline Baseline $^{\text {a }}$ & $2(3,8)$ & $9(17,0)$ & $14(26,4)$ & $21(39,6)$ & $5(9,4)$ & $2(3,8)$ & 53 \\
3 months & $5(10,9)$ & $22(47,8)$ & $14(30,4)$ & $5(10,9)$ & 0 & 0 & 46 \\
\hline
\end{tabular}

How do you perceive your current anxiety with regards to your cardiac condition?

\begin{tabular}{|c|c|c|c|c|c|c|c|}
\hline & $\begin{array}{l}\text { No anxiety } \\
\text { at all }\end{array}$ & $\begin{array}{l}\text { Very little } \\
\text { anxiety }\end{array}$ & $\begin{array}{l}\text { Some } \\
\text { anxiety }\end{array}$ & $\begin{array}{l}\text { Moderate } \\
\text { anxiety }\end{array}$ & $\begin{array}{l}\text { Very much } \\
\text { anxiety }\end{array}$ & & \\
\hline Baseline $^{a}$ & $11(21,2)$ & $21(40,4)$ & $12(23,1)$ & $6(11,5)$ & $2(3,8)$ & & 52 \\
\hline \multirow[t]{3}{*}{3 months } & $13(28,3)$ & $15(32,6)$ & $17(37)$ & $1(2,2)$ & 0 & & 46 \\
\hline & \multicolumn{7}{|c|}{ How do you perceive your current satisfaction regarding your meeting with a physician and a nurs } \\
\hline & Excellent & Very good & Good & Fairly good & Poor & & \\
\hline Baseline $^{b}$ & $15(29,4)$ & $30(58,8)$ & $6(11,8)$ & 0 & 0 & 0 & 51 \\
\hline 3 months & $10(22,7)$ & $23(52,3)$ & $10(22,7)$ & $1(2,3)$ & 0 & 0 & 44 \\
\hline
\end{tabular}

( ) = percentage.

${ }^{\mathrm{a}}=$ before the EPS model.

${ }^{b}=$ after visit at the physician/nurse. 

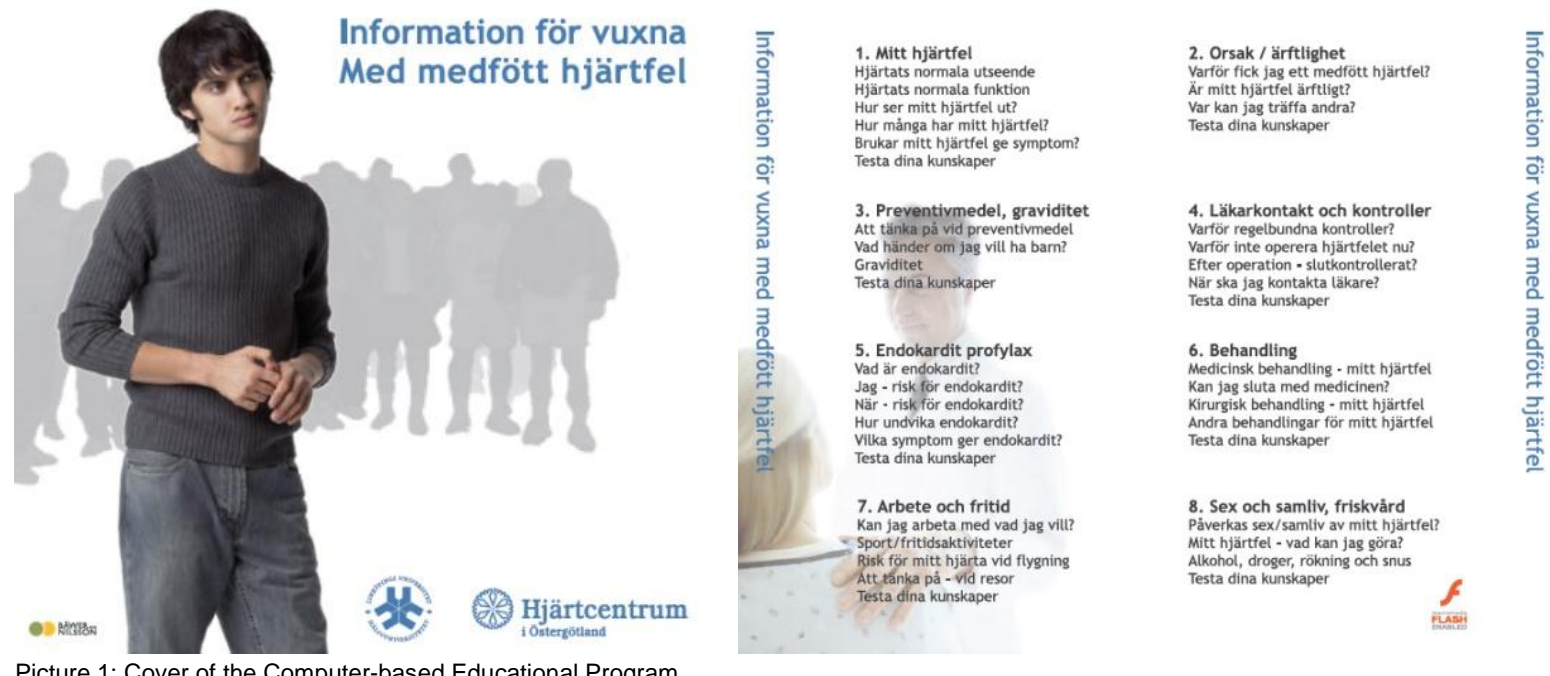

8. Sex och samliv, friskvård Paverkas sex/samtiv av mitt hjartten Alkohol, droger, röknning och snus Testa dina kunskaper 


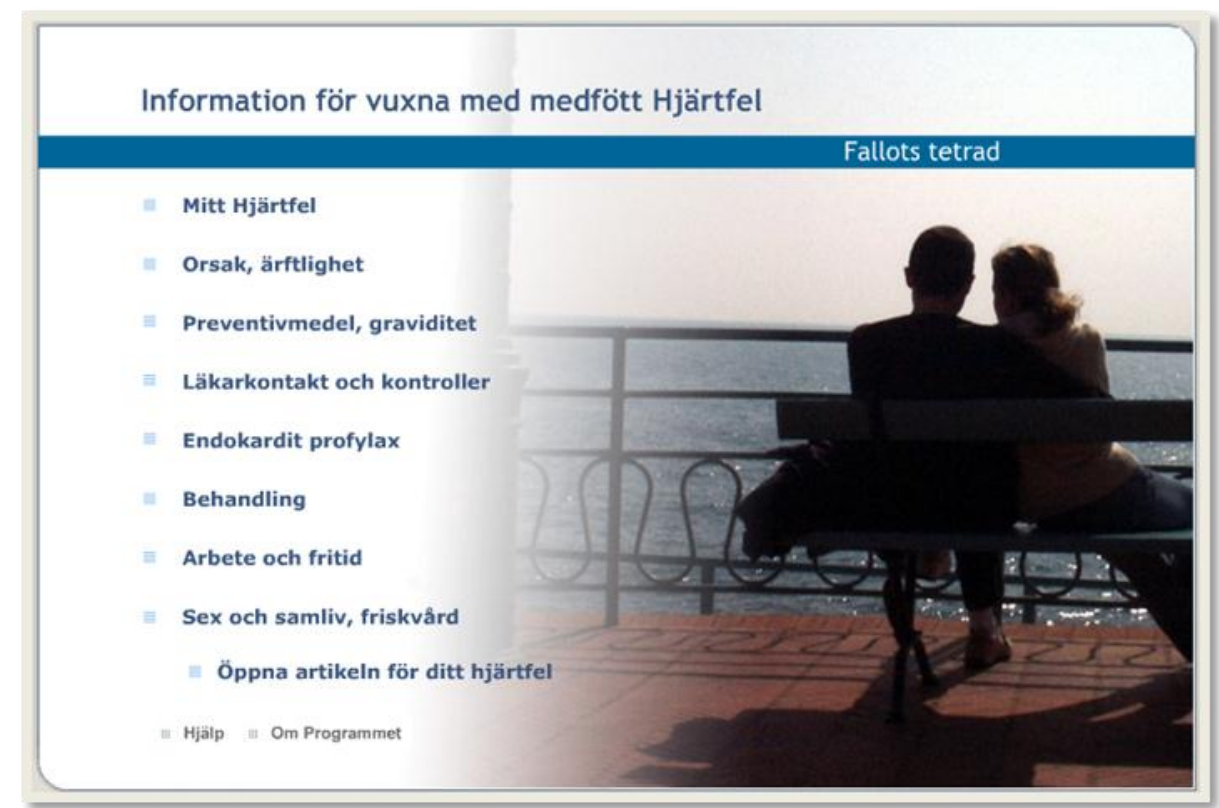

Picture 2: The main areas in the Computer-based Educational Program. 


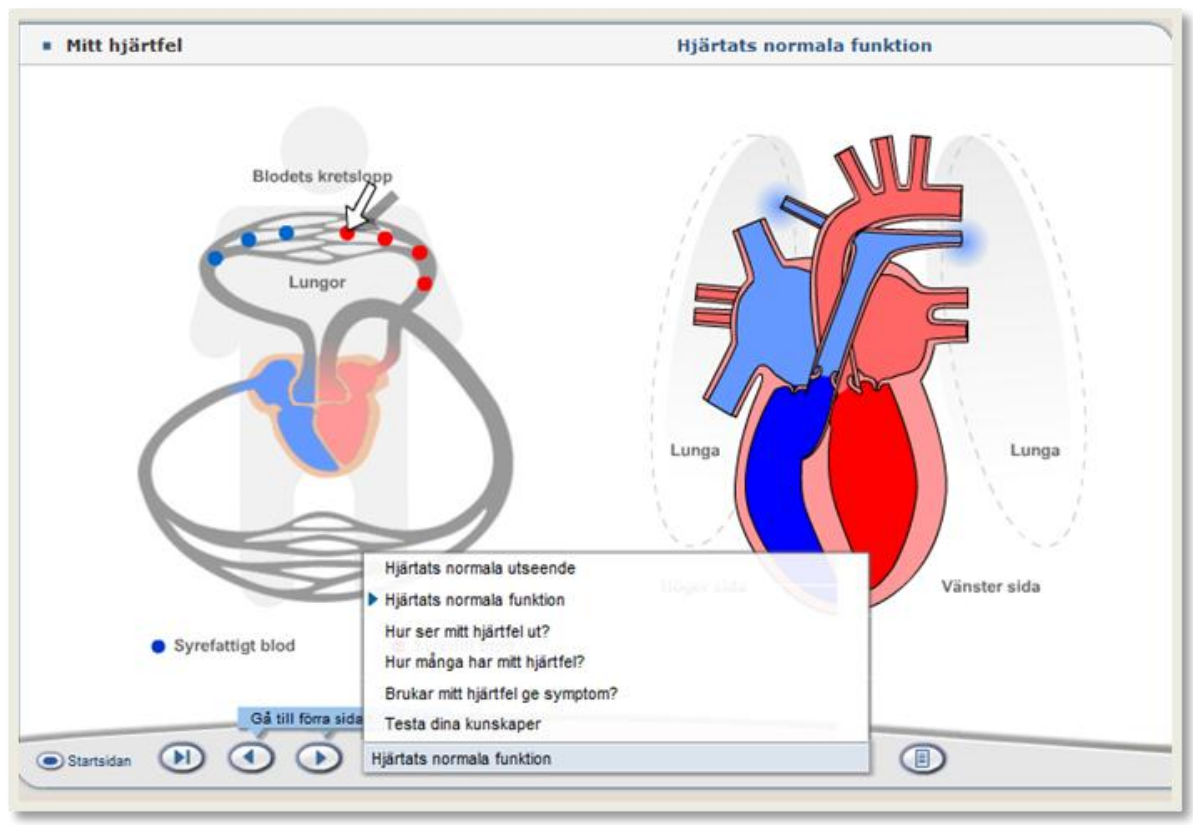

Picture 3: Example of how to navigate in the subheadings in the Computer-based Educational Program. 


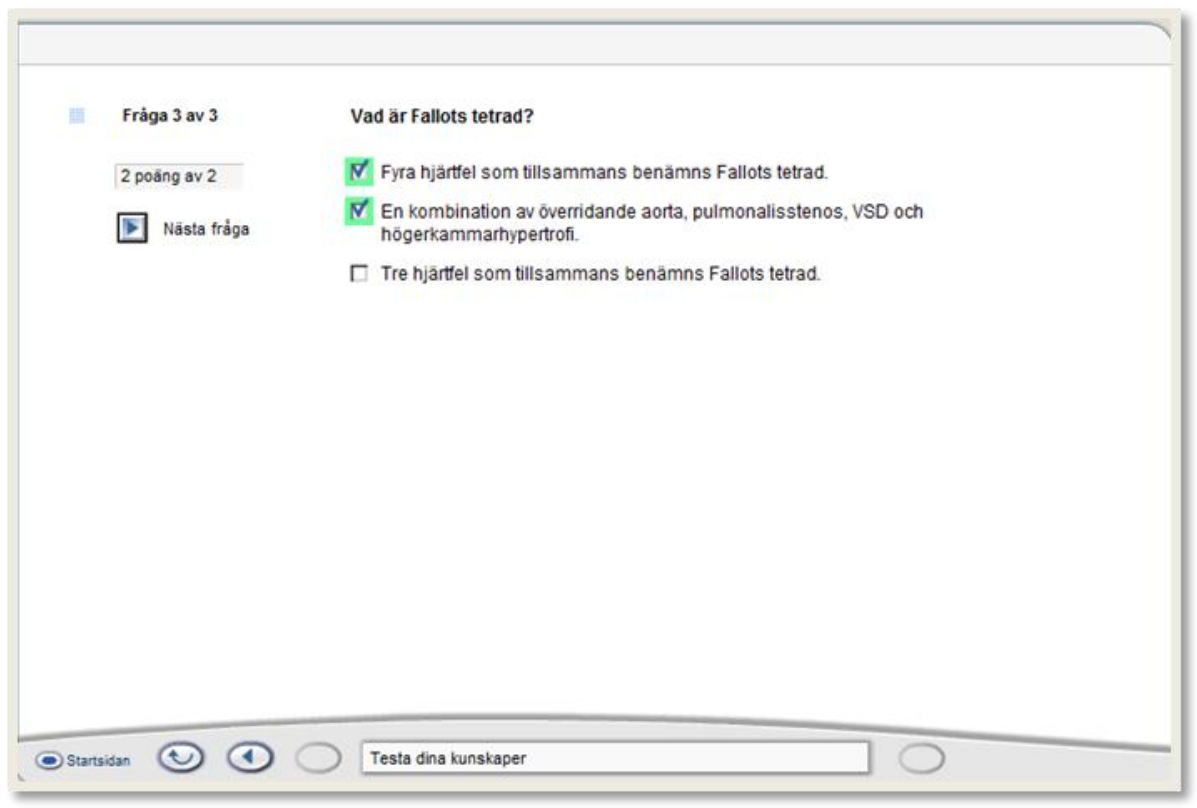

Picture 4: Example of the self-conducted test in the Computer-based Educational Program. 